\title{
Desenho Universal para a Aprendizagem (DUA) e as tecnologias digitais: rompendo barreiras promovendo aprendizagem
}

\author{
Universal Design for Learning (DUA) and digital Technologies: breakig barriers promoting \\ learning
}

\author{
Diseño Universal para el Aprendizaje (DUA) y tecnologias digitales: romper barreras \\ promovendo el aprendizaje
}

\begin{abstract}
Resumo
Este estudo tem por intuito refletir sobre as estratégias de ensino pautadas no Desenho Universal para Aprendizagem (DUA) articulado a utilização das tecnologias digitais, no contexto da Pandemia do COVID-19. Desta maneira, objetivou compreender como se desenvolveu os processos e práticas formativas desenvolvidas no modelo remoto, realizado no período letivo de 2020 e conhecer como os acadêmicos analisaram as práticas implantadas e implementadas pelos professores e identificar elementos que sinalizam para práticas pautadas no DUA articuladas ao uso das tecnologias digitais. A pesquisa, que privilegiou a abordagem qualitativa, desenvolveu-se no âmbito de uma Universidade pública estadual do Estado do Paraná e participaram turmas do quarto ano do curso de licenciatura em pedagogia e os sujeitos foram compostos por dezessete alunos. A coleta de dados ocorreu nos meses de junho e julho de 2020 e como instrumento utilizou-se um questionário contendo cinco perguntas abertas, as quais foram respondidas via Google Docs. Os discursos dos sujeitos foram organizados para análises a partir de dois temas, quais sejam: o ensino remoto alterações sem alterações: os limites vivenciados na prática e o ensino remoto e uso das tecnologias: aproximações com os princípios do Desenho Universal para a Aprendizagem. Por fim, conclui-se que os recursos tecnológicos e as mídias digitais auxiliam o "estar junto" do professor com o aluno, auxiliando seu processo de construção do conhecimento e que as mídias digitais ofertam uma gama imensa de possibilidades, desde que articuladas aos princípios do DUA.
\end{abstract}

Palavras-chave: Desenho universal para a aprendizagem; Tecnologias digitais; Mídias digitais; Ensino remoto; COVID-19.

\begin{abstract}
This study, which aims to reflect on teaching strategies based on Universal Design for Learning (DUA) articulated the use of digital technologies, in the context of the COVID Pandemic 19. Thus, it aimed to understand how the training processes and practices developed in the model remote, carried out in the 2020 academic period, to know how academics analyzed the practices implemented and implemented by teachers and to identify elements that signal for practices based on DUA articulated to the use of digital technologies. The research, which privileged the qualitative approach, was developed in the scope of a state public University of the State of Paraná and classes of the fourth year of the pedagogy degree course participated and the subject was composed of seventeen students. Data collection took place in the months of June and July 2020 and as a tool, a questionnaire containing five open questions was used, which were answered via Google Docs. The subjects' speeches were organized for analysis based on two themes, namely: remote teaching changes without changes: the limits experienced in practice and remote teaching and use of technologies: approximations with the principles of universal design for learning. It is concluded that technological resources and digital media assist the "being together" of the teacher with the student, helping their knowledge construction process and that digital media offer an immense range of possibilities, as long as they are linked to the principles of the DUA.
\end{abstract}

Keywords: Universal design for learning; Digital technologies; Digital media; Remote teaching; COVID-19. 


\begin{abstract}
Resumen
Este estudio, que tiene como objetivo reflexionar sobre las estrategias de enseñanza basadas en el Diseño Universal para el Aprendizaje (DUA) articuló el uso de tecnologías digitales, en el contexto de la Pandemia COVID 19, por lo que tuvo como objetivo comprender cómo se desarrollaron los procesos y prácticas formativas en el modelo remoto, realizado en el período académico 2020, para conocer cómo los académicos analizaron las prácticas implementadas e implementadas por los docentes e identificar elementos que señalen prácticas basadas en DUA articuladas al uso de tecnologías digitales. La investigación, que privilegió el enfoque cualitativo, se desarrolló en el ámbito de una Universidad pública estatal del Estado de Paraná y participaron las clases del cuarto año de la carrera de pedagogía y la asignatura estuvo compuesta por de diecisiete estudiantes. La recolección de datos se realizó en los meses de junio y julio de 2020 y como herramienta se utilizó un cuestionario que contenía cinco preguntas abiertas, las cuales fueron respondidas a través de Google Docs. Los discursos de las asignaturas se organizaron para su análisis a partir de dos temas, a saber: la enseñanza a distancia cambios sin cambios: los límites vividos en la práctica y la enseñanza y uso de tecnologías a distancia: aproximaciones a los principios del diseño universal para el aprendizaje. Se concluye que los recursos tecnológicos y los medios digitales ayudan al "estar juntos" del docente con el alumno, favoreciendo su proceso de construcción de conocimiento y que los medios digitales ofrecen un inmenso abanico de posibilidades, siempre que estén vinculados a los principios de DUA.
\end{abstract}

Palabras clave: Diseño universal para el aprendizaje; Tecnologías digitales; Medios digitales; Enseñanza remota; COVID-19.

\title{
1. Introdução
}

O educando é o agente principal da aprendizagem. Não existe educação, aprendizagem ou instituto de ensino sem ele. O educador é importante como intermediário entre os conteúdos e os educandos, exercendo uma ação exterior, auxiliando, coordenando, planejando, despertando, induzindo e mostrando os caminhos e os instrumentos essenciais para sua formação cultural e profissional.

(Siqueira, 2005, p. 21)

Este estudo tem por objetivo refletir sobre a importância de se estabelecer estratégias de ensino pautadas no Desenho Universal para Aprendizagem (DUA) articulado ao uso das tecnologias digitais, sobretudo, no contexto da Pandemia do COVID-19.

A Doença de Coronavírus (COVID-19) segundo Pereira et al. (2020) configura-se como uma nova enfermidade, diferente de outras causadas por um patógeno da linhagem dos coronavírus, como a Síndrome Respiratória Aguda Grave (SARS) e a Síndrome Respiratória do Oriente Médio (MERS). Trata-se de uma doença com rápido perfil de transmissibilidade entre indivíduos, que podem ser sintomáticos ou não, por isso uma das medidas de grande importância para conter a disseminação do vírus é o distanciamento social. É nesse contexto que acadêmicos e professores de uma universidade pública do Estado do Paraná se viram desafiados a reinventarem as práticas e processos de ensino e de aprendizagem.

Foi no dia 17 de março do ano de 2020 que professores e acadêmicos do curso de licenciatura em Pedagogia, se viram imersos em um contexto totalmente inimaginado até a referida data. No início, era comum o pensamento de que a suspensão das aulas era algo muito breve e que o vírus, até então, pouco ouvido e, muito menos, conhecido, não teria potencial para fazer todos "pararem” por um longo período. Fato é que as premissas não se confirmaram e, onze meses se passaram até o momento desta escrita e, junto a esse período uma nova escrita, também, impensada até o mês de março de 2020, teve que ser sistematizada.

O contexto de incertezas inquietava, assombrava e desestabilizava a muitos. Mas, uma decisão foi tomada, as aulas não parariam; o processo de ensino e aprendizagem deveria continuar e, com esse desafio, os questionamentos: Como se desenvolve os processos e práticas no formato do ensino remoto? Como os alunos analisam essas práticas, do ponto de vista de estratégias, que garantam a aprendizagem de todos? Quais os limites e possibilidades percebidas no modelo de ensino remoto? 
Com bases nestes questionamentos elencou-se como objetivo geral deste estudo compreender como se desenvolve o processo de ensino e aprendizagem no modelo remoto, delineando-se como objetivos específicos: analisar as ações que os alunos indicam como alteração das práticas dos professores e identificar elementos que sinalizam para práticas pautadas no DUA articuladas ao uso das tecnologias digitais.

Esses questionamentos inquietavam a todos, acadêmicos e professores e, ao passo que se pensava caminhos, inúmeras estratégias e ações foram sendo colocadas em prática. A ideia de que bastava adicionar no ambiente virtual, Plataforma Moodle, textos em PDF, logo tornou-se obsoleta, pouco atrativa e muito excludente.

Assim, diante deste contexto, os ajustes iam sendo demandados e, em função destes, era necessário pensar com os acadêmicos os caminhos possíveis. Tendo essa clareza, os professores lançaram mão da aplicação de um questionário contendo cinco questões, das quais para a elaboração deste artigo selecionou-se três que versaram sobre os seguintes assuntos: limites e possibilidades observadas pelos acadêmicos sobre as práticas vivenciadas no formato (atividades remotas/atividades em domicílio); alterações realizadas pelos professores no formato (atividades remotas/atividades em domicílio); motivos percebidos pelo acadêmico que impulsionou a alteração e que estratégias tecnológicas foram empregadas. Articulados a estes questionamentos que perpassavam não, apenas, pelos processos de ensino, mas, também pelo processo de aprender, engajava-se leituras compreensivas acerca de tecnologias digitais disponíveis, recursos e meios para ampliar, ao máximo, as possibilidades de aprendizagem a todos os acadêmicos. O cenário inicial se mostrava frágil precário e excludente, havia a consciência de que vários estudantes não estavam conseguindo apropriar-se dos conhecimentos o que tornava urgente a necessidade de alteração das práticas pedagógicas.

Assim, com o fim de compreender e atender tal necessidade, os professores buscavam fundamentos sobre a necessidade de se prover um currículo que todos os acadêmicos pudessem aprender. Este fato direcionou para os estudos sobre o Desenho Universal para Aprendizagem (DUA) articulado ao uso das tecnologias digitais.

Neste direcionamento, nos limites de espaço e tempo, este artigo apresenta breves apontamentos sobre o DUA e a interação entre esse e as tecnologias e mídias digitais. Na sequência faz-se uma exposição do caminho metodológico, para em seguida apresentar os resultados e discussões com o objetivo de tecer análises acerca dos conteúdos explicitados pelos os acadêmicos participantes da pesquisa.

\section{Pressuposto Teóricos Metodológicos do Estudo}

\subsection{Desenho Universal para a Aprendizagem (DUA): um início de conversa}

A educação tem de surpreender, cativar, conquistar os estudantes a todo momento. A educação precisa encantar, entusiasmar, seduzir, apontar possibilidades e realizar novos conhecimentos e práticas.

(Moran, 2007, p. 21)

Estar imersos em uma sociedade em que as tecnologias se fazem presentes em todos os segmentos da vida das pessoas, na casa, no trabalho, na escola, no lazer, provoca o repensar sobre as possibilidades conferidas por esses recursos, sobretudo, no contexto de pandemia.

É inegável, que na educação, as mídias digitais também encontram espaço: notebooks educacionais, computadores, lousa digital, celulares, tablets, entretanto, não basta ter estes equipamentos à disposição sem mudar e/ou adaptar novas metodologias; é preciso mudar a forma de ensinar e aprender. Entende-se tal como Moran (2007, p. 21-22) que, 
a escola é um dos espaços privilegiados de elaboração de projetos de conhecimento, de intervenção social e de vida. É um espaço privilegiado de experimentar situações desafiadoras do presente e do futuro, reais e imaginários, aplicáveis ou limítrofes. Promover o desenvolvimento integral da criança e do jovem só é possível com a união do conteúdo escolar e da vivência em outros espaços de aprendizagem.

Com isso, é possível ratificar que as tecnologias e mídias digitais são ótimos meios para inclusão, entretanto, incorporá-las às práticas pedagógicas do cotidiano não é uma tarefa fácil, pois conforme menciona Brito (2006, p. 5-6),

[...] do livro, ao quadro de giz, ao retroprojetor, a TV e vídeo, ao laboratório de informática as instituições de ensino vem tentando dar saltos qualitativos, sofrendo transformações que levam junto um professorado, mais ou menos perplexo, que se sente muitas vezes despreparado e inseguro frente ao enorme desafio que representa a incorporação das tecnologias ao cotidiano da sala de aula.

A necessidade de se propiciar aos professores, cursos e formação para que possam usufruir dos recursos disponíveis, há algumas décadas vem ecoando nos espaços acadêmicos. No entanto, no contexto de pandemia, em vias de ensino remoto, tal necessidade se tornou urgente, especialmente, aos professores, para que eles pudessem se apropriar dessas tecnologias, pedagogicamente, a fim de desenharem novos percursos para a aprendizagem de todos.

No contexto de pandemia, conhecer e dominar alguns recursos tecnológicos, tornou-se insuficiente, foi preciso ir além para pensar, recriar/reinventar metodologias que garantissem a todos os sujeitos, o acesso ao saber sistematizado, não como direito transcrito nas legislações, mas, que de fato as informações se transformassem em conhecimento. Entretanto, o uso dos textos em PDF, disponibilizados no ambiente virtual, se mostrou ineficaz para tal fim.

Desta forma, a conjuntura exigiu repensar as práticas desenvolvidas e lançar mão de materiais e recursos diversificados, bem como, estratégias metodológicas que considerassem o conteúdo, o contexto e as realidades subjetivas dos acadêmicos.

As mídias e os recursos disponíveis explicitavam maiores possibilidade para implementação de práticas pautadas no DUA. A flexibilidade que esse designer permite, abre um leque de interações, na medida em que viabilizam inúmeras combinações, entre texto, fala, imagem e uma ressignificação das rotas de aprendizagem, até então fixadas pelo modelo presencial. No formato remoto, essa visão da aprendizagem teve que ser reconfigurada. Tal movimento coaduna com os pressupostos que o DUA amplia os processos pelos quais os alunos acessam o conhecimento. Não, apenas, vislumbra recursos que eliminam barreiras, mas propiciam o planejamento de cursos e currículos adequados. Rappolt-Schlichtmann et al. (2013), salientam que não cabe falar de adaptação curricular. Uma das premissas do DUA é que as barreiras para a aprendizagem ocorrem na intersecção com o currículo.

Desta maneira, o currículo teve de ser redesenhado, não comportava mais, apenas seguir os tópicos programados, foi preciso pensar nas necessidades e potencialidades dos sujeitos envolvidos. Inicialmente, até se tentou seguir, rigorosamente, o currículo e os planos delineados no contexto pré pandemia, mas o modelo remoto, reivindicou novas ações; era preciso romper barreiras e promover aprendizagens. Gradativamente, uma certeza se explicitava: o modelo de pequenas adaptações e ajustes mostrou-se ineficiente, pouco atrativo e nada funcional. Tal como os princípios do DUA, uma adaptação a posteriori, pode ser de baixa atratividade e, pouco ou nada funcional. Esse princípio bem explicitando na arquitetura, onde se originou o desenho universal, mostra no dia a dia o quão as adaptações de espaços, mobiliários e recursos exclusivistas são caras e, muitas vezes, inadequadas.

Do ponto de vista do currículo, Pastor; Sánchez Serrano e Zubillaga del Río (2018), mencionam que a mesma relação é possível, haja vista que, muitas vezes, tais investimentos, em adaptações, são poucos funcionais, pois nem sempre levam ao objetivo original. Limitam-se a remendos, tal como, de borracharia com usabilidade restrita e muito breve, aposta 
em simplificações que não garantem a aprendizagem a todos. Outro aspecto importante que se deve levar em consideração diz respeito ao baixo nível de interesse que essas adaptações provocam. Inicialmente, pela sua essência exclusivista e, ao se colocar desta forma, já nega uma condição essencial para a aprendizagem que é a possibilidade de aprender juntos. Fato este que causa deslocamento e pouca motivação.

Outros fatores levantados pelos autores supracitados está na onerosidade acarretada ao professor, que se vê diante do desafio de pensar individualidades e, na necessidade de se criar várias "caixinhas" de opções, para aqueles que leem com dificuldade um texto extenso num equipamento inapropriado como o celular, aqueles que não tem muita disponibilidade para falar diante dos colegas, aqueles que não se sentem à vontade para abrir as câmeras e se expor ao grupo, aqueles que necessitam de interações mais ativas do professor e que o Ambiente Virtual de Aprendizagem (AVA) tornou-se um limitador. Enfim, os docentes se viram diante de um desafio em que tinham que pensar nas variáveis intermináveis do contexto remoto para conseguir fazer seu trabalho de modo a atender aos alunos.

$\mathrm{O}$ desafio foi redesenhar a rota, renunciar ao modelo presencial e ingressar plenamente num modelo remoto que garantisse aprendizagem, despertasse interesses e não fosse tão custoso de se colocar em prática. A resposta a esse desafio estava em buscar os princípios do DUA articulando-os aos recursos tecnológicos e midiático que o professor e aluno dispunham.

Nesse contexto, o Desenho Universal para a Aprendizagem, mediados pelas tecnologias digitais, surgiu como uma alternativa metodológica possível para que todos os acadêmicos pudessem acessar ao conhecimento, independente, do nível cognitivo e intelectual.

Partiu-se do pressuposto que a interação entre as tecnologias digitais e o DUA contribuem para a eliminação de barreiras metodológicas nos contextos educacionais de ensino remoto. Houve a compreensão de que o currículo, neste contexto e, na perspectiva do DUA, precisava,

estar ligado à vida, ao cotidiano, fazer sentido, ter significado, ser contextualizado. Muito do que os alunos estudam está solto, desligado da realidade deles, de suas expectativas e necessidades. O conhecimento acontece quando algo faz sentido, quando é experimentado, quando pode ser aplicado de alguma forma ou em algum momento (Moran, 2007, p, 23).

Foi neste direcionamento que o novo desenho, agora para o modelo remoto, possibilitou a participação mais ativa dos acadêmicos; incentiva-os a criarem ações flexíveis. Fato este evidenciado nas suas apresentações que explicitou avanços e compreensões de suas relações com o conhecimento.

Neste sentido, as inquietações não, apenas do ponto de vista das ações pedagógicas, mas, também da compreensão conceitual do que seria o DUA, fez-se necessária e comungou para que houvesse a clareza de que pequenos reparos não daria conta do que o momento exigia. Entranto, iquietações surgiram o que é DUA onde surgiu essas ideias?

Os fundamentos em que os professores estavam imersos, foi evidenciando que a expressão Desenho Universal (DU) surge nos Estados Unidos, nos anos de 1980, com a ideia que o design dos ambientes e produtos devem ser, previamente, pensados a fim de atender maior número de pessoas, sem que se tenha de fazer adaptações posteriores. "Universal design is the design of all products and environments to be usable by people of all ages and abilities, to the greatest extent possible"1 (Mace et al., 1991 apud Story \& Mueller, 2011, p. 32.1)

\footnotetext{
${ }^{1}$ O Design Universal é o design de todos os produtos e ambientes para serem usados, na medida do possível, por pessoas de todas as idades e habilidades. (tradução livre realizado pelas autoras).
} 
Segundo Bock, Gesser \& Nuernberg (2018, p. 148), o DU tem suas origens com Ronald Mace, arquiteto e diretor do Centro sobre o Desenho Universal no North Carolina State University (NCSU). Ele introduziu o Desenho Universal (UD), em 1985, na concepção de produtos e de ambientes para que o maior número de pessoas pudesse utilizá-los sem a necessidade de adaptações, ou seja, na medida do possível, os recursos da construção civil podem ser utilizados por todos os sujeitos.

Mendes (2017) corrobora que:

tal concepção não decorre somente da busca de respostas para demandas sociais de setores que reivindicavam a plena participação de todos. Havia também uma percepção de que adaptações não planejadas voltadas à acessibilidade de prédios ou residências, às vezes chamadas de "puxadinhos", eram caras, esteticamente feias e reforçavam o rótulo de "incapacidade" das pessoas com deficiência. Por outro lado, ficava evidente que tais ajustes acabavam beneficiando uma ampla gama de pessoas, dos mais variados perfis e idades.

Se a princípio predominou a questão estética, posteriormente, o desenho universal teve por intuito beneficiar a vida das pessoas, independente da sua posição social.

É a partir daí que o Desenho Universal para a Aprendizagem (DUA) chega à educação por iniciativa de um grupo de professores da Universidade de Harvard, sob a liderança de David Rose. A inquietação destes docentes foi uma tentativa de garantir que todos os alunos tivessem acesso aos conteúdos curriculares de forma igualitária, haja vista, que os currículos são elaborados para turmas heterogêneas, sem levar em consideração que cada aluno assimila as informações, adquire conhecimento de forma própria e apresenta habilidades motoras, intelectuais e sensoriais distintas.

No entanto, Rose et al. (2006), alertam de que embora o Design Universal já esteja consolidado na arquitetura e áreas afins, na educação, ainda, é relativamente recente e, mesmo que seja familiar para alguns educadores, sua aplicação ainda tem um longo caminho a ser percorrido, pois não se pode simplesmente transferir metodologias aplicadas ao design de produtos, edifícios e/ou ambientes para o ensino-aprendizagem sem adaptações.

Na linha dos pressupostos do DUA, em que se pense o ensino para todos, não se esquecer que "o currículo precisa ser repensado para que se torne importante para o aluno, para que este se sinta protagonista, sujeito, personagem principal. A escola tem de se adaptar ao aluno e não o contrário" (Moran, 2007, p. 23). O contexto do ensino remoto exigia repensar a prática pedagógica frente a um currículo e planejamento pensado para contextos de interações físicas.

Neste sentido o DUA "se apresenta como um conjunto de possibilidades - materiais flexíveis, técnicas e estratégias - que busca ampliar a aprendizagem de alunos com ou sem deficiência. O objetivo é atingir assim, um número maior possível de alunos, universalizando, portanto, a aprendizagem" (Movimento Down, 2015).

O pressuposto de que Desenho Universal para a Aprendizagem (DUA) e seu conjunto de princípios e estratégias possibilitam ao docente desenvolver práticas pedagógicas curriculares acessíveis a todos os alunos, ou seja, que permitem que todos tenham acesso ao ensino e à aprendizagem de forma igualitária, independente, de suas capacidades cognitivas e intelectuais, de que maneira as tecnologias e/ou mídias digitais podem contribuir para incluir todos os sujeitos no processo de aprendizagem, foi perseguido no contexto do ensino remoto gerando questionamentos sobre como se dava a interação desse princípio com tecnologias e as mídias.

\subsection{Interação entre o DUA, Tecnologias e Mídias Digitais}

É importante humanizar as tecnologias: são meios, caminhos para facilitar o processo de aprendizagem. É importante também inserir as tecnologias nos valores, na comunicação afetiva, na flexibilização do espaço e tempo do ensino-aprendizagem.

(Moran, 2007, p. 38) 
Antes de refletir sobre a interação entre o Desenho Universal de Aprendizagem, tecnologias e mídias digitais, é importante esclarecer o que se entende por estes vocábulos. Então vejamos. Tecnologia é um termo polissêmico e seu significado varia conforme os avanços da sociedade. Neste sentido, Bueno (1999, p. 87), consideramos como:

um processo contínuo através do qual a humanidade molda, modifica e gera a sua qualidade de vida. Há uma constante necessidade do ser humano de criar, a sua capacidade de interagir com a natureza, produzindo instrumentos desde os mais primitivos até os mais modernos, utilizando-se de um conhecimento científico para aplicar a técnica e modificar, melhorar, aprimorar os produtos oriundos do processo de interação deste com a natureza e com os demais seres humanos.

Neste aspecto, a tecnologia vai além da utilização dos equipamentos, mas permeia as relações do sujeito consigo próprio, com a natureza e com os demais seres humanos. Vieira Pinto (2005, p. 702), alerta de que a tecnologia é

sempre um bem, pelo simples fato de constituir um acréscimo ao conhecimento humano, a expansão da cultura, na verdade um aspecto da manobra da hominização, mesmo quando impiedosa na aplicação, em virtude das condições sociais ou dos interesses dos agentes a que serve. Em princípio, a tecnologia, sendo propriedade social, em sentido econômico e ético, representará um benefício para o homem se a sociedade que a engendra e utiliza for, ela própria, um bem para o homem.

Percebe-se, assim, que a tecnologia acompanha o processo histórico em totalidade, haja vista ela ser fruto do trabalho humano e, por isso, pertence a todos e, por pertencer a todos, também concede a todos o direito de dela apropriar-se. Motivo pelo qual entende-se que ela necessita ser orientada para servir de forma homogênea, para que todos dela possam fazer e usufruir de seus benefícios.

Entende-se por mídia digital qualquer conteúdo que utiliza da internet para sua distribuição e possibilita feedback por parte do receptor em tempo real.

$\mathrm{O}$ uso das tecnologias móveis que acessam à internet, tais como celulares e tablets, é uma realidade presente em muitas salas de aulas por parte de alunos e professores para acessar as informações de maneira rápida e eficaz. Algumas escolas já inseriram estas mídias em suas metodologias de ensino para facilitar a aprendizagem de forma inovadora.

De acordo com Mendes (2017), o "DUA se trata de um modelo prático que visa ampliar as oportunidades de desenvolvimento de cada estudante por meio de planejamento pedagógico contínuo, somado ao uso de mídias digitais".

$\mathrm{O}$ autor supracitado menciona que as mídias digitais:

desempenham um papel muito significativo para quem pretende trabalhar a partir do Desenho universal para a aprendizagem. Sua flexibilidade abre portas para diversos percursos de aprendizagem, na medida em que viabilizam inúmeras combinações entre texto, fala, imagem e uma ressignificação do erro, que pode passar a ser tratado como parte natural do processo de aprendizagem (Mendes, 2017).

Vários outros autores têm demonstrado a importância do uso de recursos tecnológicos combinados com o DUA para promover a aprendizagem de todos os alunos. O uso tradicional de recursos como lousa, livro didático, aula expositiva, no ensino remoto foram colocados em xeque, pois agora era necessário por força das circunstâncias lançar mão do uso de tecnologias; restava saber, o que e como utilizar. Neste sentido, foi preciso repensar as aulas e, além de tudo, aulas inclusivas onde todos os alunos pudessem interagir.

Apesar de que há muito tempo pesquisadores discutirem que os recursos tecnológicos adicionam à aula um significativo grau de motivação, pois facilitam as opções de apresentação e expressão dos conteúdos, com recurso de imagens, áudios, textos de áudio descrição, aplicativos que redigem o texto após um ditado, o contexto do ensino remoto 
ratificou o que já haviam anunciado os teóricos que abordam sobre o uso das tecnologias digitais para processos de aprendizagens interativas. Estava posto a oportunidade ideal para refletir sobre uso das tecnologias articulando-as ao desenho universal para aprendizagem.

Nesta linha, cumpre destacar com Sancho (2006), o qual afirma que as tecnologias não melhoram por si mesma o processo de aprendizagem, uma vez que requer seleção do tipo de recursos articulados ao planejamento sobre como se utilizar dos meios digitais para alcançar os objetivos curriculares. Trata-se de uma advertência importante e corroborada por Silva (2000), quando afirma que é possível, por um lado se utilizar apenas de um texto em PDF e garantir boa interação e significativa aprendizagem e, por outro lado, uma gama de recursos tecnológicos utilizados de forma ineficiente, o que leva a refletir sobre como se está sendo utilizado a gama de recursos e plataformas digitais?

Para responder a esse questionamento é necessário entender as ferramentas digitais na sua distinção, ou seja, o enfoque reativo ou enfoque proativo, conforme classificado por Edyburn (2010).

As tecnologias de enfoque reativo: compreendem as tecnologias assistivas e servem para possibilitar o acesso aos conteúdos por pessoas com algum tipo de deficiência sensorial e/ou cognitiva, como o caso dos sintetizadores de voz, VLibras, NVDA entre outros. Já as tecnologias de enfoque proativo: são aquelas que auxiliam na criação de materiais digitais com o fim de melhorar a aprendizagem pautando-se nos princípios do DUA. Elas objetivam proporcionar múltiplas formas de compromisso; de representação e; de ação e expressão.

O compromisso compreende a motivação, ou seja, só se aprende aquilo que de algum modo prende o interesse, pois a atenção será mais centrada, no entanto, a motivação implica mais ação que simplesmente a captura de determinadas fontes de interesses. A conduta motivada relaciona-se aos valores atribuídos às ações ou as vivências. A partir desta valoração é que os sujeitos se definem por manter um dado engajamento ou alterar sua ação.

A motivação, por sua vez, tem a dimensão inata e adquirida. No espaço educativo, a adquirida tem maior significado, pois expressa a interação entre ensino e aprendizagem e evoca a necessidade da ação colaborativa, como os murais interativos (Padlet), as Wiki, a Base de dados, o Google Keep, os mapas conceituais em equipe, entre outros recursos que possibilitam maior interatividade, colaboração e engajamento motivacional.

Por sua vez, as formas de representações relacionam-se a disponibilização de diversas ferramentas para criar materiais que abrem diferentes opções de representação, ou seja, diferentes canais de informação para assegurar o acesso aos conteúdos. Podem utilizar tecnologias com enfoque reativos que garantam a acessibilidade aos conteúdos como os sintetizadores de voz, VLibras, NVDA, Teclado contraste com o fim de atender pessoas com alguma deficiência, com distúrbios de aprendizagem, ou mesmo, limitação temporária. Além dessas tecnologias, pode-se, também, utilizar em conjunto tecnologias proativas as quais permitem a combinação de texto escrito com notas de áudio, links de navegação, vídeos e, permitem, até adicionar um documento em PDF ou apresentação de slides, além de vários aplicativos disponíveis que também possuem sua versão online, tais como: Pages, iBooks Author, Bookcreator, Keynote e Thinglink.

Por fim, o princípio das múltiplas formas de ação e expressão, relaciona-se com as possibilidades de expressar o aprendido por meio de ferramentas diversificadas como as já citadas anteriormente, ou ampliar o repertório impulsionando maior criatividade, como usar o Canva para criar um infográfico interativo; podem responder oralmente às proposições enviando áudio, um Podcast ou um Thinglink, adicionar voz ou imagem, além de permitirem a criação de vídeos com o iMove, dentre outros. Estudantes que optam por expressão visual podem, também, criar com Mark Beliefs Comix.

Esses recursos e ferramentas geram uma gama de diversificação para a expressão e ação, capaz de acomodar as especificidades de cada estudante. Os smartphones, os tablets, os notebooks e os livros digitais ilustram esse tipo de tecnologia, capaz de ampliar substancialmente os horizontes de desenvolvimento de cada aluno. 
Em suma, cumpre destacar que as mídias digitais ofertam uma gama imensa de possibilidades as quais podem ser articuladas aos princípios do DUA ratificando o assinalado por Moran (2007, p, 23) ao afirmar que,

O aluno formado por internet e multimídia e que está sempre conectado está pronto para aprender com os colegas a desenvolver atividades significativas, a contribuir em cada etapa de um projeto. O currículo precisa ser repensado para que se torne importante para o aluno, para que este se sinta protagonista, sujeito, personagem principal. A escola tem de se adaptar ao aluno e não o contrário.

Assim, em acordo com Brito (2006) o conceito de inclusão digital se amplia juntamente com o entendimento do que seja as tecnologias e de que para ser incluído é preciso que o professor compreenda que:

- uma boa utilização das tecnologias na educação pode propiciar a criação de novas formas de relação pedagógica, de novas formas de pensar o currículo e, portanto, pode também conduzir a mudanças no ambiente escolar;

- o uso das tecnologias na educação tem um potencial enorme, que, não está diretamente relacionado à presença da máquina, mas sim do profissional professor que firmou um compromisso com a pesquisa, com a elaboração própria, com o desenvolvimento da crítica e da criatividade, superando a cópia, o mero ensino e a mera aprendizagem.

\subsection{Os Passos Metodológicos}

A pesquisa científica se apresenta como um edifício, da dimensão dos arranha-céus, que supõe a mobilização de um exército de técnicos e inventores, trabalhando em equipes disciplinas e que dispõe de orçamentos da importância de um tesouro do Estado.

(Cervo \& Bervian, 2002)

Os fenômenos que se desenvolvem do contexto educacional têm, historicamente, se constituído objetos de pesquisa como um desafio às ciências sociais. No contexto da pandemia, não tem sido diferente, já que questões históricas emblemáticas sobressaltaram neste contexto de virtualidade. A complexidade do momento, exigiu a observância e análises das práticas desenvolvidas no meio remoto, com vistas a filtrar compreensões e buscar soluções para os problemas que emergiram.

\subsubsection{Tipo do estudo}

Para a realização deste estudo exigiu-se opção teórica, a qual definiu também o método "a escolha do método, metodologia e técnicas a utilizar" (Richardson, 1999, p. 32).

Inúmeros desafios se colocam a respeito da organização metodológica e, consequente, a escolha do tipo de pesquisa que atenda as demandas do processo. Desafio este que consistiu em compreender como se desenvolvia o processo de ensino aprendizagem no modelo remoto, buscando analisar ações que os alunos indicam como alterações de práticas de um modelo presencial para o modelo remoto e identificar elementos destas práticas que sinalizavam para práticas pautadas no DUA articuladas ao uso das tecnologias digitais.

Neste direcionamento, esta pesquisa delineou-se pelos estudos exploratórios que, segundo Pereira et al. (2018) é um meio para se estudar um fenômeno pouco explorado e que requer aprofundamentos teóricos e empíricos. A abordagem de análise está pautada na pesquisa qualitativa que, em acordo com André et al. (2013) é uma pesquisa cujo desafio consiste em compreender os aspectos que implicam na formação do humano, de suas relações e construções culturais, em suas 
dimensões grupais, comunitárias ou pessoais. Esta pesquisa, assinala a autora não é neutra e pressupõe a integração contextual e a compreensão de significados nas dinâmicas histórico-relacionais.

Os autores supracitados afirmam, ainda, que na pesquisa qualitativas os dados coletados são predominantemente descritivos, partindo da análise do pesquisador e de sua compreensão do todo para a reflexão sobre o que pode ser ou não elucidado, uma vez que descrição visa possibilitar um diálogo com o objeto. Trata-se de uma metodologia que se preocupa mais com o processo do que com o produto, pois é nessa fase que se constrói as hipóteses que nortearão a própria pesquisa e possibilitarão a formulação descritiva necessária para a construção do conhecimento. A abordagem qualitativa é "a justificativa para que o pesquisador mantenha um contato estreito e direto com a situação onde os fenômenos ocorrem naturalmente" (Lüdke \& André, 2013, p. 12).

Realizar a pesquisa no meio onde o sujeito está inserido se faz necessário, com o fim de refletir acerca dos valores e os significados que os acadêmicos atribuíam às condições de aprendizagem no modelo remoto. Diante disso, realizar a pesquisa com fundamentos qualitativos é coerente à medida que se aspira mais em "retratar a perspectiva dos participantes" (Bogdan; Biklen apud Lüdke \& André, 2013).

$\mathrm{Na}$ abordagem qualitativa, a técnica investigativa de caráter exploratório é marco para a compreensão e análise dos fenômenos em questão, uma vez que esses são vividos e revelados nas inferências de cada um dos acadêmicos que contribuíram para a realização desta pesquisa. Para Sampieri (1998, p. 58),

[...] os estudos exploratórios se efetuam, normalmente, quando o objetivo é examinar um tema ou problema de investigação pouco estudado ou que não tenha sido abordado anteriormente, isto é, quando a revisão da literatura revelou que há linhas não investigadas e ideias vagamente relacionadas ao problema de estudo.

\subsubsection{O Campo da Pesquisa}

A pesquisa foi realizada no âmbito de uma Universidade Pública Estadual do Estado do Paraná, com turmas do quarto ano do curso de licenciatura em Pedagogia.

Interessou, a realização desta pesquisa neste contexto pelo fato de os alunos e professores estarem vivenciando situações distintas do modelo que vinham praticando até o dia 17 de março de 2020, ou seja, saíram de um formato presencial para o formato remoto em questão de horas, entre a divulgação da portaria nesta data, suspendendo as aulas presenciais, mas, que as suas continuidades, agora seriam totalmente a distância, o que se convencionou chamar, no âmbito desta instituição, ensino remoto.

\subsubsection{Os Sujeitos}

Para participarem da pesquisa foram convidados os 35 alunos que estavam participando do modelo remoto, desses 17 acadêmicos devolveram ICD respondidos. No âmbito deste artigo, são analisadas as respostas de cinco acadêmicos, todos os sujeitos foram identificados pelas letras Ac (abreviatura de acadêmico), seguido de um número sequenciado de um a cinco, conforme números de respostas para análises neste artigo. Sendo os sujeitos (Ac.1); (Ac.2); (Ac.3); (Ac.4); (Ac.5).

O critério de inclusão, nesta da amostra, permeou pelos sujeitos que conseguiram participar das atividades no modelo remoto. Esse critério foi importante, pois, havia acadêmicos que necessitavam ir até a instituição para retirar materiais e atividades físicas. 


\subsubsection{Procedimentos para coleta dos dados}

Para investigar os objetivos expostos na introdução deste trabalho realizou-se o estudo exploratório por meio de questionários no Google Forms que a própria instituição aplicava para monitorar alunos que tinham equipamentos e dados para continuarem no sistema remoto e que se dispunham a participar neste modelo.

A análise realizada aos questionários aplicados pela instituição viabilizou a organização do roteiro formulado com quatro questões abertas assim definidas:

- Sobre as práticas vivenciadas no formato (atividades remotas/atividades em domicílio) que limites e possibilidades você tem observado?

- Houve a necessidade de alterações realizadas pelos professores no formato (atividades remotas/atividades em domicílio)?

- Quais foram e que motivos você percebe que impulsionou a alteração?

- Que estratégias tecnológicas têm sido empregadas?

Essas questões foram aplicadas por e-mail e junto ao questionário foi encaminhado o Termo de Consentimento Livre e Esclarecido (TCLE) os quais foram devolvidos com a devida assinatura dos participantes. Antes da aplicação foi realizada uma reunião com os acadêmicos, via plataforma Meet, na qual foi esclarecido os objetivos e importância da pesquisa para o momento, as questões da ética na pesquisa, questões de preservação da identidade e não acarretamento em ônus para ambos, pesquisados e pesquisador que a participação não implicava risco à saúde, além de ser totalmente voluntária, podendo haver a negativa em participar a qualquer etapa da pesquisa.

A coleta dos dados ocorreu nos meses de junho e julho de 2020. Todos os relatos foram transcritos adequando-se à condição de escrita e acrescidos de anotações de inferências dos sujeitos ocorridas nos momentos em que foram aplicados os questionários pela instituição.

\subsubsection{Procedimentos para análise dos dados}

Orientando-se pelos princípios da pesquisa qualitativa e considerando-se a abrangência no trato de fenômenos nãoquantificáveis, a coleta de dados foi efetivada por meio de aplicação de questionário. Compreende-se que a análise, a que se propôs, toma forma e sentido à medida que os sujeitos têm a possibilidade de expressar suas inferências.

O aporte teórico sócio histórico reforça a importância de ouvir os sujeitos. Assim, os discursos dos sujeitos, após descritos em planilhas, foram organizados para análises a partir de dois temas:

a) ensino remoto alterações sem alterações: os limites vivenciados na prática

b) ensino remoto e uso das tecnologias: aproximações com os princípios do Desenho Universal para a Aprendizagem

Aqui seguiu-se as recomendações propostas por Richardson (1999), que menciona que o meio mais rápido e eficaz, consiste em isolar temas específicos, bem como, as partes de maior relevância consoante ao problema pesquisado.

\section{Resultados e Discussão}

[...] a educação deveria mostrar e ilustrar o Destino multifacetado do humano: o destino da espécie humana, o destino individual, o destino social, o destino histórico, todos entrelaçados e inseparáveis. 
Com o fim de compreender como se desenvolveu os processos e práticas formativas desenvolvidas no modelo remoto, realizado no período letivo de 2020 e identificar como os acadêmicos analisaram a práticas implantadas e implementadas pelos professores, buscou-se apreender a partir de seus apontamentos os limites e possibilidades vivenciados, bem como, as alterações que foram vivenciando ao longo do processo.

\subsection{Ensino remoto alterações sem alterações: os limites vivenciados na prática}

É preciso criar pessoas que se atrevam a sair das trilhas aprendidas, com coragem de explorar novos caminhos. Pois a ciência construiu-se pela ousadia dos que sonham e o conhecimento é a aventura pelo desconhecido em busca da terra sonhada.

(Rubem Alves)

As análises aqui ensejadas não podem prescindir do que se entende por ensino remoto e ensino a distância. Corroborando com Silva (2000), a modalidade EaD baseia-se na configuração operacional transmissivo e massivo, onde os principais atores são os responsáveis por elaborar os conteúdos de aprendizagem ao cursista, comumente solitário, que fica incumbido de ler e responder as atividades e propostas num ambiente virtual. Essa configuração culmina na fragmentação do processo que, pela natureza unidirecional, inibe a mediação docente e a interação entre professor e estudantes e entre os próprios estudantes.

Por sua vez o ensino online, que é base para o ensino remoto, amplamente divulgado, debatido e mesmo questionado no período letivo de 2020, requer a clara compreensão sobre as necessidades que se apresentam, numa abordagem de caráter mais transmissivo massivo e na abordagem mais construtiva em que a prioridade está em propiciar as condições para que se construam conhecimentos.

Esse modelo de ensino requer uma configuração permeada pelo uso das tecnologias digitais, mas, sobretudo, pela capacidade de se realizar mediações docentes nas quais a proximidade, ainda que virtual, entre os sujeitos do processo é condição sine qua non para a efetivação da aprendizagem/presencialidade virtual.

Esse formato de ensino requer uma adequação dos propósitos pedagógicos aos recursos tecnológicos onde o paradigma comunicacional, da internet social ou da web 2.0., ou a internet dos blogs, das wikis e das redes sociais, contribuam para se desenvolver a autoria, o compartilhamento, a conectividade e a colaboração; palavras fundamentais para o processo de construção do conhecimento (Silva, 2020).

Tal evidência distintiva entre a abordagem unidirecional e uma abordagem mais dialógica ficou explícita no modelo de ensino remoto desenvolvido em 2020, sobretudo, aos sujeitos que, até o momento da necessidade de distanciamento social, pouco ou nada haviam se envolvido em atividades semipresenciais fundadas no modo virtual, com a utilização quase que exclusiva de recursos tecnológicos digitais e, tampouco, haviam se envolvidos com práticas pautadas no Desenho Universal para Aprendizagem, conforme ressaltaram os $\mathrm{AC}(1,2,3,4$ e 5) sequencialmente,

“Alguns professores que não passavam tanto conteúdo e trabalhos em sala (no presencial), agora a distância têm enviado mais textos e atividades”. (AC1, 2020)

"Minha preocupação é referente aos conteúdos dados aos alunos e não ter compreendido da forma adequada. Os professores estavam habituados com a presencial, tivemos muitas dificuldades!” (AC2, 2020)

"No início as atividades eram apenas leituras e resumos, seguiam o mesmo do presencial, mas sem as explicações, estava muito difícil acompanhar! Seguimos apenas cumprindo tarefas e prazos". (AC3, 2020) 
"Na minha concepção existe um divisor, pois para quem entende da tecnologia e consegue acessar é algo que ajuda parcialmente no aprendizado, já aos alunos que nem tecnologias tem fica difícil, além, disso a falta de mediação do professor, que fez muito mais falta, diante do excesso de textos para ler e atividades com prazos restritos". (AC4, 2020)

"Os esforços empregados, nos garantem a continuidade de nosso calendário acadêmico, o papel de cada professor, garante essa continuidade. Porém, há muitas dificuldades sofridas em ambas as partes, alguns somente nos expõem os textos e nos pedem as atividades, não havendo dialogo para maior compreensão. Então tivemos que alterar as práticas que de fato não foram muito alteradas, pois a lógica que se seguiu, na proposição das atividades, foi a do ensino presencial, só que sem a mediação do professor”. (AC5, 2020).

Notadamente, nas falas desses acadêmicos, está explícito o quanto da urgência de se alterar as práticas de ensino e aprendizagem no contexto do ensino remoto 2020, pois como constatam os acadêmicos pesquisados, os professores "têm enviado mais textos e atividades" (AC1, 2020). Isto evidencia que não houve alterações significativas de fato.

O sentimento de isolamento, tão presente no modelo EaD unidirecional o que tem sido apontado como causa de evasão nos cursos à distância, também, foi percebido no ensino remoto como assinalou AC5 (2020) "alguns somente nos expõem os textos e nos pedem as atividades, não havendo diálogo para maior compreensão”.

O uso das tecnologias não garantiu a efetiva participação no que se refere à construção do conhecimento, sendo que um dos fatores postos pelos acadêmicos, foi a falta da mediação docente articulada ao excesso de leituras e tarefas para responder, como indicou AC4 (2020):

"para quem entende da tecnologia e consegue acessar é algo que ajuda parcialmente no aprendizado, já aos alunos que nem tecnologias tem fica difícil, além, disso a falta de mediação do professor, que fez muito mais falta, diante do excesso de textos para ler e atividades com prazos restritos". (AC4, 2020).

Ainda nesta linha, destaca-se as palavras de AC2 (2020):

"Depois que passamos a ter aulas via Zoom, nossas condições de aula melhoraram, mas nada se compara ao proveito das aulas presenciais, em que a troca entre professores e alunos se dá com muito mais proveito, até porque, nem sempre a tecnologia funciona como se espera, às vezes a qualidade da chamada via Zoom não é tão boa".

Nota-se que apesar de estar participando das aulas esse acadêmico vê o formato remoto como um limitador à aprendizagem o que reporta à ideia de que tanto professores quanto os alunos foram chamados a um processo complexo e intenso de adaptações à nova realidade.

Os limites vivenciados na prática do ensino remoto por professores e acadêmicos reportam a um conceito, um tanto distanciado das práticas desenvolvidas com base em ambientes virtuais, definido por Valente (2003) como "o estar junto virtual", que pressupõe, conforme o autor é a proposição de situações que viabilizem a construção de conhecimento envolve o acompanhamento e assessoramento constante do aprendiz no sentido de poder entender quem ele é e o que faz, para ser capaz de propor desafios e auxiliá-lo a atribuir significado ao que está realizando.

Nas análises do autor, o advento das tecnologias digitais permite tal interação e tem como objetivo a realização de espirais de aprendizagem, facilitando o processo de construção de conhecimento (Valente, 2002). Isso requer, no entanto, que o aluno seja engajado na resolução de um problema ou projeto o que, geralmente, é contraditório à proposição de excesso de leituras para a realização de tarefas. No entanto, assinala o autor, a implantação de processo de construção de conhecimento, vias tecnologias digitais, implica mudanças profundas no processo educacional, as quais até mesmo a educação presencial ainda se debate. No modelo remoto as novas demandas, que levou professores a explorarem facetas 
potenciais das tecnologias digitais até então desconhecidas, conduzindo a percepção de que, as tecnologias se apresentam como recursos que podem facilitar o processo de mudanças na educação (Axt \& Fagundes, 1995; Fagundes, 1996; Prado \& Valente, 2002). Embora, o momento inicial do ensino remoto tenha desvelado limites a continuidade ensejou alterações reais que viabilizaram a configuração do próximo tema.

\subsection{Ensino remoto e uso das tecnologias: aproximações com os princípios do Desenho Universal para a Aprendizagem}

"A tecnologia, para ser útil, precisa antes de tudo ser necessária".

(Vieira Pinto, 2005, p. 301)

Como assinalado em acordo com os apontamentos de Cast (2011) o currículo que segue os pressupostos do DUA é delineado, desde o início para atender a todos os alunos de uma turma. No entanto, como visto nos apontamentos dos acadêmicos, é notório que nos primeiros momentos de ensino remoto, não havia a preocupação de que o trabalho a ser desenvolvido precisava atender a necessidade de todos. Assim, os próprios limites vivenciados no processo inicial, indicava a necessidade de alterações e de flexibilização, seja de conteúdos, de objetivos e, sobretudo, de estratégias e recursos, principalmente, no contexto de ensino remoto.

A necessidade de manter calendário, conteúdos e a continuidade do processo de ensino aprendizagem exigiu o repensar das práticas, a escuta aos alunos com o fim de reavaliar e propor o que fosse necessário. $\mathrm{O}$ ato da escuta aos alunos implicou na possibilidade de o professor repensar a forma como vinha desenvolvendo o ensino remoto e, para além disso, perceber em que medida o que vinha sendo proposto contribuía para a construção do conhecimento. Conforme destaca o AC1 (2020)

"Dentre as 8 professoras que temos, noto que cada uma se adaptou da melhor forma para atender as demandas da turma. Tem professoras agendando aulas pelo Zoom toda semana, outras há cada 15 dias. Pela minha experiência, estou conseguindo acompanhar bem os estudos de todas as matérias, mas vejo que consigo ter outras reflexões dos textos a partir do momento que temos a aula pelo zoom com discussão do assunto com os colegas da turma e comentários da professora".

O apontamento desse acadêmico reporta ao que pontuou Valente (2002) sobre o estar junto virtual, isto é, a partir da mediação docente, caminhos se abrem para que o aluno possa continuar a resolução do problema e, as dúvidas que possam surgir, poderão ser resolvidas por meio da mediação pedagógica que o professor realiza a distância. A interação com os colegas, também, é um aspecto importante, pontuado por este acadêmico, que se percebe num ciclo de ações, no processo de realização de atividades inovadoras, o qual gera conhecimentos sobre como desenvolver essas ações, porém, com o suporte do professor, assim que os recursos tecnológicos e as mídias digitais auxiliam o "estar junto" do professor com o aluno, auxiliando seu processo de construção do conhecimento.

Outro aspecto importante acerca desta temática é indicado na seguinte fala:

"no início tanto os professores como os alunos estavam encontrando dificuldades, mas agora sinto que estamos conseguindo trabalhar todos os conteúdos necessários, por meio das aulas por vídeos, por reuniões para debater os temas e pelas atividades". (AC2, 2020)

Esta fala é corroborada por Silva (2000) e Sancho (2006), os quais assinalam que as tecnologias não melhoram por si mesma o processo de aprendizagem, pois, tem-se a necessidade de se selecionar recursos e estratégias planejadas e articuladas aos objetivos curriculares. 
Silva (2000), salienta, ainda, que é possível, por um lado, se garantir a interação e significativa aprendizagem com apenas um texto em PDF e, por outro lado, uma gama de recurso tecnológicos subutilizados. Notadamente, pela fala do acadêmico, os aspectos mais significativos do processo está na interação, na mediação docente e na preocupação em garantir aprendizagem significativa, conforme indicou o acadêmico:

"há professores usando outras ferramentas tecnológicas além do Moodle, como o Zoom e Whatssapp para trabalhar os temas das aulas e esclarecer dúvidas, que têm contribuído significativamente para a aprendizagem, até mesmo para tornar esse processo de estudo à distância um pouco mais confortável. Do início das aulas remotas para esse momento houve a necessidade de um retorno, uma readequação, como por exemplo, ter reuniões após as leituras. Isso nos ajuda na compreensão". (AC2, 2020)

Percebe-se, assim, que os esforços coletivos de professores por estratégias que possibilitassem a participação de todos foram evidenciados pelos acadêmicos em suas falas.

Embora, no contexto inicial do ensino remoto, não houvesse nenhuma discussão acerca do Desenho Universal para Aprendizagem, os professores imbuídos da necessidade de prover a mediação docente, estudaram, pesquisaram e buscaram lançar mão de recursos tecnológicos e estratégias diversas com o fim de garantir maior participação e interação dos acadêmicos, tais preocupação também, são indicadas pelos acadêmicos,

"Os recursos tecnológicos de midias digitais usadas para o acesso como moodle, zoom, email e até mesmo o whats estão sendo de ótima ajuda para que não percamos esse ano letivo e possamos aprender". (AC1, 2020)

Nota-se que as indicações dos alunos são sobre a necessidade de maior interação e mais possibilidades de recursos e meios para participarem. Este fato está em consonância com Moran (2007) quando assinala que o aluno que está sempre conectado está pronto para aprender com os colegas e desenvolver atividades significativas e, assim, pode atuar como protagonista de seu conhecimento; por isso ressalta o autor, a escola precisa adaptar-se ao aluno e, não, o contrário.

A aproximação com os pressupostos do DUA é evidenciada, também na lógica pela qual se organiza o processo de ensinar e aprender. Notadamente, o desenho universal pressupõe princípios básicos os quais dizem respeito ao compromisso, a representação e ação e expressão. Esses pressupostos podem ser identificados na seguinte fala:

"Vejo que os professores têm procurado usar materiais que sejam de mais fácil compreensão, com uma linguagem mais objetiva para nossa compreensão, além de colocarem questionamentos para nós resolvermos, isso exige também a necessidade de busca para o construir o conhecimento. Mas esse momento pede adaptações, isso sempre fez parte de nossa evolução, somos levados a buscar soluções para problemas que surgem. A escola, como uma instituição formadora, encontra se em meio a todas as dificuldades que a COVID-19 traz, mas como é composta de sujeitos estes ainda acreditam nesta instituição, por isso vejo a preocupação de que atinjamos o objetivo de uma aprendizagem significativa de se organizar um cronograma estruturado, para podermos seguir no processo agindo e participando ativamente". (AC3, 2020).

Sobre o compromisso, pode-se inferir que esse se relaciona à motivação, pois, só se aprende aquilo que de algum modo desperta o interesse. Estar focado e centrado é diferente de simplesmente capturar determinadas fontes de interesses. Essa postura, por sua vez, relaciona-se aos valores atribuídos às ações ou vivências. A partir desta valoração é que os sujeitos se definem por manter um dado engajamento ou alterar sua ação. Pode-se inferir que foi o compromisso que manteve o aluno centrado nos objetivos de continuar o curso superior, mas, também as alterações que foram sendo propostas pelos professores. Do ponto de vista de recursos, metodologias e interação entre professor-aluno e aluno-aluno, também, contribuiu para que a motivação fosse mantida.

Outro aspecto, também, pontuado na fala do acadêmico que reporta ao princípio do DUA, é a representação. Esse definida como as múltiplas formas de representação, ou seja, a disponibilização de diversas ferramentas para criar materiais que abrem diferentes opções de representação, ou seja, diferentes canais de informação para assegurar o acesso aos 
conteúdos, com destaque aos recursos proativos que permitiram a combinação de texto escrito com notas de áudio, links de navegação, vídeos e, até adicionar um documento PDF ou apresentação de slides, dentre outros.

Está posto, também o princípio das múltiplas formas de ação e expressão, o qual tem a ver com as possibilidades que foram postas aos alunos para expressarem o aprendido por meio de ferramentas diversificadas, como as já citadas anteriormente, ou ampliar o repertório impulsionando maior criatividade. Pode-se ressaltar que as ferramentas geram uma gama de diversificação para a expressão e ação, capaz de acomodar as especificidades de cada estudante e, por fim, ampliam substancialmente os horizontes de desenvolvimento de cada acadêmico.

Os acadêmicos 4 e 5 assinalam, ainda, que:

"Observei que houve alteração por parte dos professores, que buscam alternativas para suprir a falta das aulas presenciais por meio de indicação de filmes e documentários para fazermos relações com os assuntos estudados, além dos textos que temos lido. São aspectos que já existiam na prática de muitos professores, mas que se tornou mais frequente e mais rica a aprendizagem". (AC4, 2020)

"Os professores estão se esforçando para que todos os alunos não sejam prejudicados com os conteúdos e as atividades. Estão disponíveis para tirar as nossas dúvidas no zoom e pelo whatsapp que auxilia parcialmente no aprendizado. Utilizam recursos como Moodle, Zoom, E-mail, Classroom e Whatsapp, além de estratégias pedagógicas diversas com áudio, imagem, vídeo e textos o que viabilizam a apreensão do conteúdo por diversos canais". (AC5, 2020)

Em síntese, as mídias digitais ofertam uma gama imensa de possibilidades, desde que articuladas aos princípios do DUA.

\section{Considerações Finais}

Normalmente, a gente não produz conhecimento totalmente novo, no sentido de uma construção nova. Nós partimos do que já está construído, do que já está disponível, do conhecimento que está aí diante de nós e o refazemos, reelaboramos.

(Pedro Demo)

Este estudo que teve como objetivo compreender como se desenvolveu os processos e práticas formativas no modelo de ensino remoto em tempos de pandemia do COVID-19 em uma universidade pública do Estado do Paraná, Brasil, no período letivo de 2020 e, permitiu concluir que, no que diz respeito aos limites vivenciados na prática há evidente distinção entre as abordagens unidirecional e a dialógica.

Verificou-se, também, que no início das atividades no modelo remoto, o uso das tecnologias não garantiu a efetiva participação no que se referiu à construção do conhecimento, sendo que um dos fatores postos pelos acadêmicos, foi a falta da mediação docente articulada ao excesso de leituras e tarefas para responder via Plataforma Moodle. Fato este que gerou sentimento de isolamento por parte dos alunos.

Desta maneira, os limites vivenciados na prática do ensino remoto por professores e acadêmicos reportam a um conceito, um tanto distanciado das práticas desenvolvidas com base em ambientes virtuais, a interação.

A respeito do ensino remoto, o uso das tecnologias e as aproximações com os princípios do Desenho Universal para a Aprendizagem, observou-se que, embora, no momento inicial do processo de ensino remoto, não houvesse nenhuma discussão acerca do DUA, os professores imbuídos da necessidade de prover a mediação docente lançaram mão de recursos tecnológicos e estratégias diversas com o fim de garantir maior participação e interação dos acadêmicos. 
Nesse contexto, foi possível concluir que a aproximação com os princípios básicos do DUA (compromisso, representação e ação e expressão) é evidenciada, também na lógica pela qual se organizou o processo de ensinar e aprender, durante o período de ensino remoto, analisado neste artigo.

Em vias de finalização, ficou evidente, também, a necessidade de outros estudos acerca da efetivação da aprendizagem por parte dos alunos e, também a forma como o professor percebeu aspectos referentes a tal efetivação. É interessante analisar, ainda quais recursos tecnológicos e mídias digitais, dentre os estiveram ao acesso do professor, contribuiu para o processo de ensino de forma a garantir interações e aprendizagem.

\section{Referências}

Axt, M., Fagundes, L. (1995) EAD - Curso de especialização via internet: buscando indicadores de qualidade. In: Congresso Internacional Logo, 7 , Congresso de Informática Educativa do Mercosul, 1, 1995. Porto Alegre. p.120-31.

Bock, G.L.K., Gesser, M. \& Nuernberg, A.H. (2018). Desenho Universal para a Aprendizagem: a Produção Científica no Período de 2011 a 2016. Rev. bras. educ. espec., Bauru, 24(1): 143-160. http://www.scielo.br/scielo.php?script=sci_arttext\&pid=S1413-65382018000100143\&lng=pt\&nrm=iso

Brito, G. S. (2006). Inclusão Digital do profissional professor: entendendo o conceito de tecnologia. In: $30^{\circ}$ Encontro Anual ANPOCS, 2006 . Anais do Encontro (GT24). Caxambu, MG, 2006. http://www.anpocs.com/index.php/encontros/papers/30-encontro-anual-da-anpocs/gt-26/gt24-14/3475-gbritoinclusao/file

Bueno, N. L. (1999). O desafio da formação do educador para o ensino fundamental no contexto da educação tecnológica. 1999. Dissertação (Mestrado) CEFET-PR, Curitiba.

Cervo, A. L. \& Bervian, P. A. (2002). Metodologia científica: para uso dos estudantes universitários. 9. ed. São Paulo: MaKron Books.

Deckers, L. (2001). Motivation. biological, psychological and environmental. Boston: Allyn and Bacon.

Edyburn, D. L. (2010). Would you recognize Universal Design for Learning if you saw it? Ten propositions for new directions for the second decade of UDL. Learning Disability Quarterly, 33 (1): 3341.

Fagundes, L.C. (1996). Educação a distância em Ciência e tecnologia: o Projeto EducaDi/CNPq - 1997. Em Aberto, 16 (20): 134-140, abr./jun.

Fernández-Abascal, EG., Martín, MD. \& Domínguez, J. (2001). Procesos psicológicos. Madrid: Editorial Pirámide.

Lüdke, M. \& André, M. (2013) A pesquisa em educação: abordagens qualitativas. 2 ed. Rio de Janeiro: E.P.U.

Mendes, R. H. (2017). Uma educação orientada para diferenças. O Estado de S. Paulo, 24 nov. https://educacao.estadao.com.br/blogs/educacao-eetc/\%c2\%aduma-educacao-orientada-para-as-diferencas/

Morin, E. (2004). Os sete saberes necessário para a educação do futuro. 9. ed. São Paulo: Cortez.

Moran, J. M. (2007). A educação que desejamos: novos desafios e como chegar lá. 2. ed. Campinas, SP: Papirus.

Movimento Down. (2015). Manual do desenho universal para aprendizagem. Desenho universal para livros didáticos: oficina brasileira. Rio de Janeiro. http://www.movimentodown.org.br/wp-content/uploads/2015/08/Manual-FINAL-bibliografia.pdf

Palmero, F. (2005). Motivación: conducta y proceso. Revista electrónica de motivación y emoción, 8 (20-21): 1-26.

Pastor, C. A., Zubillaga, A. \& Sánchez, J. M. (2015). Tecnologías y Diseño Universal para el Aprendizaje (DUA): experiencias en el contexto universitario e implicaciones en la formación del profesorado. RELATEC-Revista Latinoamericana de Tecnología Educativa, 14 (1): 89-100.

Pastor, C. A. Sánchez Serrano, J. M.; Zubillaga del Río, A. (2018) Diseño Universal para el Aprendizaje (DUA): pautas para su introducción en el currículo. [Chile]. https://educrea.cl/diseno-universal-aprendizaje-dua-pautas-introduccion-curriculo/

Pereira, A. S. et al. (2018) Metodologia da pesquisa científica [recurso eletrônico]. Santa Maria, RS: UFSM, UAB/NTE/UFSM. 1 e-book https://repositorio.ufsm.br/bitstream/handle/1/15824/Lic_Computacao_Metodologia-Pesquisa-Cientifica.pdf?sequence=1

Pereira, M. D. et al. (2020). Sofrimento emocional dos enfermeiros no contexto hospitalar frente à pandemia de COVID-19. Research, Society and Development, v. 9(8): e67985121.

Pinto, A. V. (2005). O conceito de tecnologia. 2. ed. Rio de Janeiro: Contraponto.

Prado, M. E. B. B.; Valente, J. A. A. (2002) Educação a distância possibilitando a formação do professor com base no ciclo da prática pedagógica. In: Moraes, M. C. Educação a distância: fundamentos e práticas. Campinas: Unicamp/NIED.

Rappolt-Schlichtmann, G. et al. (2013). Universal Design for Learning and elementary school ccience: exploring the efficacy, use, and perceptions of a web-based science notebook. Journal of Educational Psychology, 105 (4): 1210-1225 nov.

Richardson, R. J. (1999). Pesquisa social: métodos e técnicas. 3. ed. rev. ampl. São Paulo: Atlas. 
Research, Society and Development, v. 10, n. 1, e52310112045, 2021

(CC BY 4.0) | ISSN 2525-3409 | DOI: http://dx.doi.org/10.33448/rsd-v10i1.112045

Rose, D. H., Harbor, W. S., Johnston, C. S., Daley, S. G. \& Abarbanell, L. (2006). Universal design for learning in postsecondary education: reflections on principles as their application. Journal of Postsecondary Education and Disability, 19 (2) 135-151.

Sampieri, R. H.; Collado, C. F. \& Lucio, P. B. (1998). Metodologia de pesquisa. 3. ed. São Paulo: McGraw-Hill Interamericana do Brasil.

Sancho, J. M.; Hernándes, F. et al. (2006). Tecnologias para transformar a educação. Porto Alegre: Artmed,

Sanz, M.T., Menéndez, F.J. \& Del Prado, M. (2019). Fundamentos teóricos y prácticos de la motivación. Madrid: Sanz y Torres.

Silva, M. (2000) Sala de aula interativa. Rio de Janeiro: Quartet.

Siqueira, M. A. da S. (2005) Monografias e teses: das normas técnicas ao projeto de pesquisa: teoria e prática. Brasília: Editora Consulex.

Wakefield, M. A. (2011). CAST (2011). Universal Design for Learning Guidelines version 2.0. https://udlguidelines.cast.org/more/downloads. Acesso em: dez. 2020. 